\title{
Dermatitis neglecta: a challenging diagnosis in psychodermatology
}

Sofia Lopes ${ }^{1 凶}$, Júlia Vide ${ }^{1}$, Isabel Antunes ${ }^{1}$, Filomena Azevedo ${ }^{1}$

\begin{abstract}
Dermatitis neglecta is a condition affecting the skin caused by a lack of hygiene. It may be related to psychiatric and neurological disturbances. The appearance of skin lesions results from neglect, which helps distinguish this condition from other similar clinical entities. Resolution of the lesions with adequate cleansing aids a definitive diagnosis.
\end{abstract}

Keywords: psychodermatology, unwashed dermatosis, omission

Received: 8 November 2017 | Returned for modification: 5 January 2018 | Accepted: 10 January 2018

\section{Introduction}

Psychodermatology is an emerging area in dermatology that involves the complex interaction of the skin and mind (1). Several entities are included in this category, and various classifications have previously been proposed (1).

Dermatitis neglecta, also known as unwashed dermatosis, is a condition secondary to a lack of hygiene that leads to an accumulation of sebum, sweat, and corneocytes, forming a compact and adherent crust of dirt $(2,3)$. Lesions result from neglect and may have various causes, including a psychiatric condition, physical disability, or neurological deficit $(3,4)$.

\section{Case report}

A 37-year-old female was referred to our dermatology department due to hyperkeratotic lesions on the face, trunk, and right arm associated with progressive weakness of the right arm that had evolved during the past 3 years. She had a medical history of anxiety, for which she was not medicated. She affirmed that the clinical findings appeared after she had left her last job. Clinically, we observed greasy, dark hyperkeratotic plaques on the face, upper anterior trunk, and right arm as well as a persistent flexion of her right wrist (Figs. 1-2).

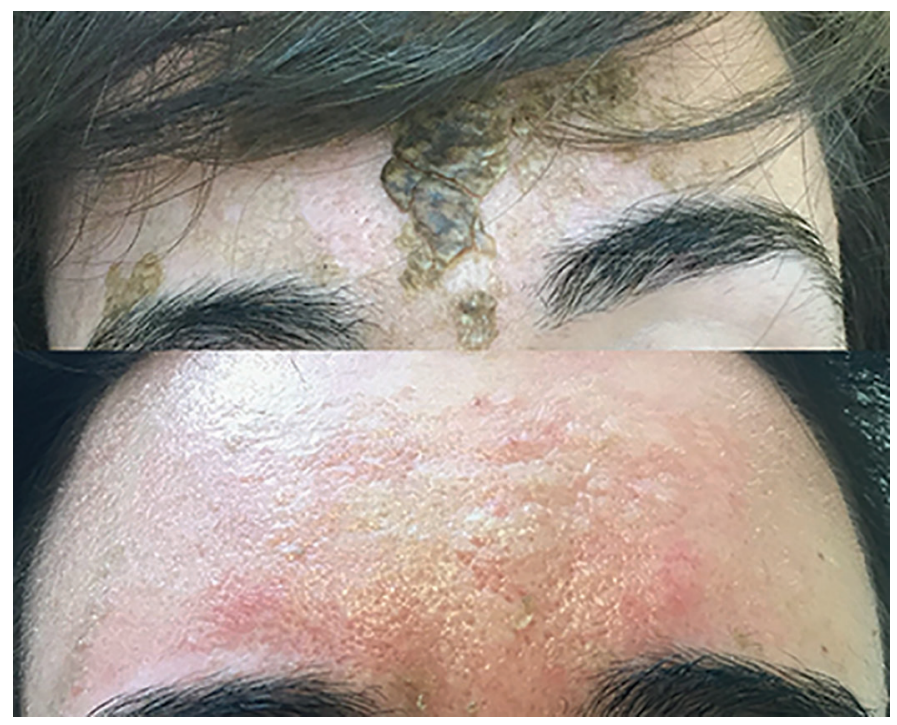

Figure 1 | Hyperkeratotic lesions in the frontal region and right hemiface.

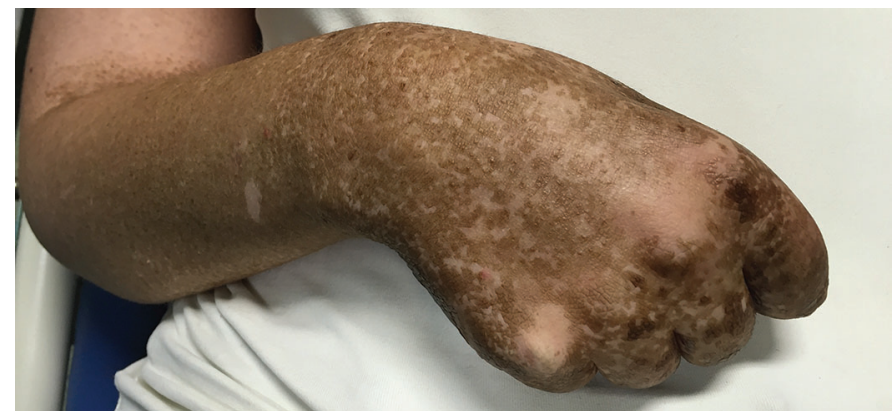

Figure 2 | Multiple hyperkeratotic lesions on the right arm and flexion of the patient's right wrist.

Given the suspicion of psychodermatosis, we applied petrolatum jelly to her facial lesions and waited a few minutes. The lesions were almost totally cleared with removal of dirt and debris and exposure of normal skin after the treatment, corroborating the diagnosis of dermatitis neglecta (Figs. 1 and 3). The patient did not report any lack of hygiene in the affected areas.

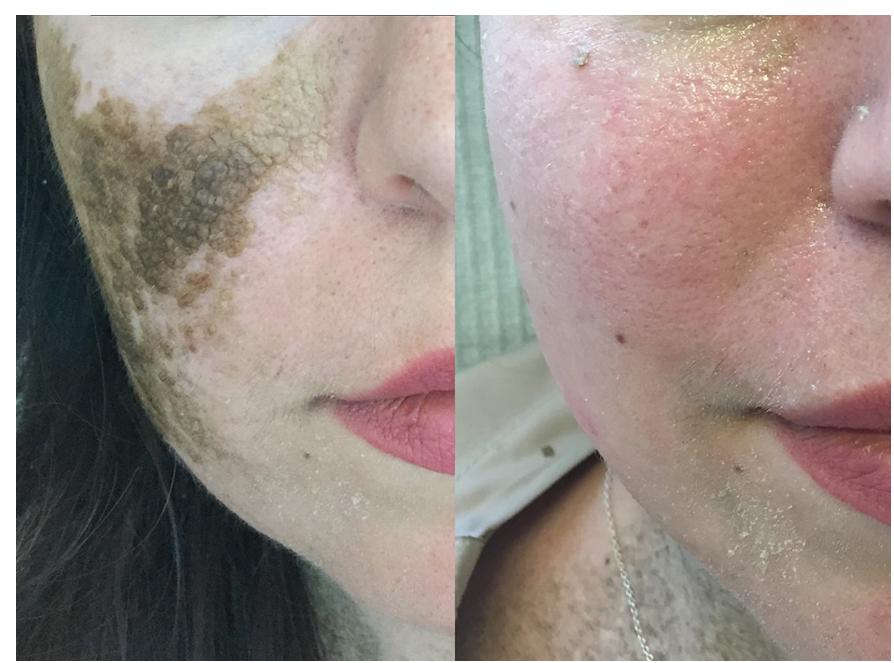

Figure 3 | After the application of petroleum jelly, lesions were removed and normal skin was exposed.

In order to exclude neurological disorders, we requested a neurologist's evaluation. She had an inconsistent neurological exam. Her electromyography revealed signs of acute partial denervation of the hand muscles, and magnetic resonance imaging showed no abnormalities, raising the possibility of a psychiatric condition. The patient was also evaluated by the orthopedics and internal 
medicine department, without consistent signs of organic pathology. After the last assessment and given the inconsistency of the data, she refused to repeat the electromyography and also rejected a psychiatric evaluation. After our last assessment, she abandoned all consultations.

\section{Discussion}

Dermatitis neglecta was first described by Poskitt et al. in 1995 (5). It has no gender predilection, affects all ages, and is frequently underdiagnosed (4). Clinically, there are asymptomatic hyperkeratotic plaques with cornflake-like scales (2-4).

Several differential diagnoses must be investigated, such as dermatitis artefacta and terra firma-forme dermatosis. Dermatitis artefacta may be classified as an impulsive-aggressive type of obsessive-compulsive disorder in which lesions result from self-injuries or from injuries worsened by the patient (1-6). Terra firma-forme dermatosis differs from dermatitis neglecta because there is no history of inadequate hygiene or response to cleansing with soap and water (2). Entities such as verrucous nevi, acanthosis nigricans, confluent and reticulate papillomatosis, and postinflammatory hyperpigmentation also have to be excluded $(3,7)$. One previous report described generalized dermatitis neglecta that mimicked psoriasis vulgaris (6).

Because rubbing the affected area with gauze soaked in alco-

\section{References}

1. Han YJ, Kim SY, Choi HY, Myung KB, Choi YW. A case of dermatitis neglecta. Ann Dermatol. 2008;20:257-9.

2. Saha A, Seth J, Sharma A, Biswas D. Dermatitis neglecta-a dirty dermatosis: report of three cases. Indian J Dermatol. 2015;60:185-7.

3. Saritha M, Karthikeyan K. Dermatitis neglecta-to be remembered, not neglected! Indian Dermatol Online J. 2015;6:138-9.

4. Perez-Rodriguez IM, Munoz-Garza FZ, Ocampo-Candiani J. An unusually severe case of dermatosis neglecta: a diagnostic challenge. Case Rep Dermatol. 2014;6:194-9.

5. Poskitt L, Wayte J, Wojnarowska F, Wilkinson JD. “Dermatitis neglecta”: unwashed dermatosis. Br J Dermatol. 1995;132:827-9.

6. Park JM, Roh MR, Kwon JE, Lee KY, Yoon TY, Lee MG, et al. A case of generalized dermatitis neglecta mimicking psoriasis vulgaris. Arch Dermatol. 2010; 146:1050-1. hol or soap and water leads to complete resolution of the lesions, adequate hygiene measures should be applied and are sufficient for the majority of patients $(1,2)$. Urea, retinoic acid, and alpha hydroxy acids may also be recommended in severe cases (4).

After revising the reports described in the literature, we found that each one reveals different backgrounds and features drawing attention to the multiplicity of lesions that this dermatosis may adopt. The majority of them resulted from lack of hygiene after surgical intervention or due to previous dermatosis, sunburn, or trauma $(2,3,5,7-10)$. Another case described is related to lack of hygiene after a facial peeling (11). There are also reports in patients with local hyperesthesia or psychiatric conditions, including depression and schizophrenia, or even related to religious beliefs $(4,10,12)$. Although this may contribute to a challenge in distinguishing this condition from other entities, its diagnosis is still clinical (4).

\section{Conclusion}

Dermatitis neglecta is a diagnostic challenge because it may mimic other dermatoses. It is crucial to bear this entity in mind in order to avoid unnecessary skin biopsies and complex therapeutic measures as well as to target patients' needs through multidisciplinary approaches.
7. Panda M, Patro N, Samant S, Arora S. Dermatitis neglecta as a complication after cataract surgery. Indian J Ophthalmol. 2016;64:231-2.

8. Sasaya EM, Ghislandi C, Trevisan F, Ribeiro TB, Mulinari-Brenner F, Gaiewski CB. Dermatosis neglecta. An Bras Dermatol. 2015;90:59-61.

9. Cinotti E, Perrot JL, Labeille B, Cambazard F. Dermatitis neglecta after airbag deployment. J Eur Acad Dermatol Venereol. 2016;30:707-8.

10. Saha A, Seth J, Bindal A, Samanta AB, Gorai S, Sharma A. Dermatosis neglecta: An increasingly recognized entity with review of literature. Indian J Dermatol. 2016;61:450-2.

11. Lucas JL, Brodell RT, Feldman SR. Dermatosis neglecta: a series of case reports and review of other dirty-appearing dermatoses. Dermatol Online J. 2006;12:5.

12. Singh P, Kar SK, Kumari R, Gupta SK. Dermatosis neglecta in schizophrenia: a rare case report. Indian J Psychol Med. 2015;37:93-5. 